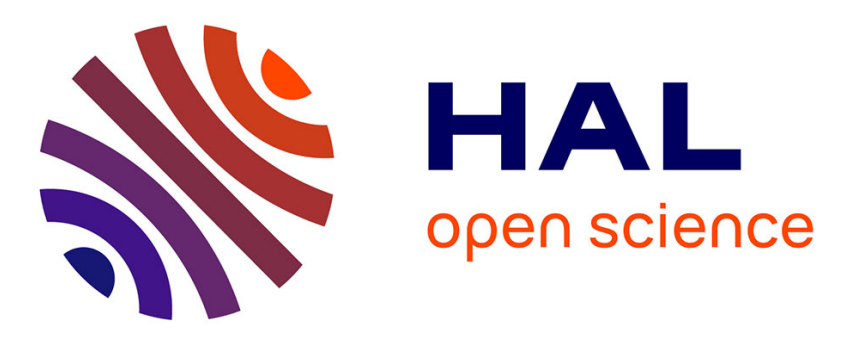

\title{
Immuno-inflammatory predictors of stroke at follow-up in patients with chronic non-valvular atrial fibrillation (NVAF)
}

Antonio Pinto, Antonino Tuttolomondo, Alessandra Casuccio, Domenico Di

Raimondo, Riccardo Di Sciacca, Valentina Arnao, Giuseppe Licata

\section{To cite this version:}

Antonio Pinto, Antonino Tuttolomondo, Alessandra Casuccio, Domenico Di Raimondo, Riccardo Di Sciacca, et al.. Immuno-inflammatory predictors of stroke at follow-up in patients with chronic non-valvular atrial fibrillation (NVAF). Clinical Science, 2009, 116 (10), pp.781-789. 10.1042/CS20080372 . hal-00479446

\section{HAL Id: hal-00479446 https://hal.science/hal-00479446}

Submitted on 30 Apr 2010

HAL is a multi-disciplinary open access archive for the deposit and dissemination of scientific research documents, whether they are published or not. The documents may come from teaching and research institutions in France or abroad, or from public or private research centers.
L'archive ouverte pluridisciplinaire HAL, est destinée au dépôt et à la diffusion de documents scientifiques de niveau recherche, publiés ou non, émanant des établissements d'enseignement et de recherche français ou étrangers, des laboratoires publics ou privés. 


\section{Immuno-inflammatory predictors of stroke at follow-up in patients with chronic non-valvular atrial fibrillation (NVAF)}

Pinto A. ${ }^{*}$; Tuttolomondo A. ${ }^{1}$; Casuccio A. ${ }^{2}$; Di Raimondo D. ${ }^{1}$, Di Sciacca R. ${ }^{1}$; Arnao V. ${ }^{2}$; Licata . $^{1}$

* These authors contribute equally to the article

${ }^{1}$ Department of Internal and Specialist Medicine, University of Palermo

${ }^{2}$ Clinical Neuroscience Department, University of Palermo 


\begin{abstract}
Objective: To determine rates of stroke in patients with chronic nonvalvular atrial fibrillation (NVAF) evaluating the relationship between plasma levels of inflammatory variables at admission and the occurrence of stroke during a three year follow-up.

Methods: 373 consecutive patients with chronic NVAF were enrolled. Blood samples were drawn within 72 hours of admission. We evaluated plasma levels of IL-1 $\beta$, TNF- $\alpha$, IL-6, IL-10, E-selectin, P-selectin, ICAM-1 VCAM-1 and Von Willebrand Factor (vWF). Patient subsequent events (stroke at follow-up) were monitored over a 3 year period.
\end{abstract}

Results: At multivariate analysis only age, hypertension and high levels of IL6, TNF- $\alpha$ and vWF remained a significant predictor of a higher risk of experiencing ischemic stroke at follow-up. Moreover, plasma values of TNF- $\alpha$, IL6 and vWF showed a significant area under the ROC curve

Conclusion: Baseline plasma levels of TNF- $\alpha$, IL- 6 and vWF are predictors of new onset ischemic stroke at follow-up in patients with chronic non valvular atrial fibrillation (NVAF).

\title{
Condensed abstract
}

To evaluate, the relationship between plasma levels of inflammatory variables at admission in pts with NVAF, and the occurrence of stroke at follow-up. We showed that baseline plasma levels of TNF- $\alpha$, IL-6 and vWF are associated with ischemic stroke at follow-up. 


\section{Introduction}

Atrial fibrillation (AF) is the most common of the serious cardiac rhythm disturbances and it is responsible for substantial morbidity and mortality in the general population [1]. Men and women with $\mathrm{AF}$ are at a substantially increased risk of stroke. [2]. Nevertheless, the atrial fibrillation population is heterogeneous in terms of ischemic stroke risk and there has been little agreement on how to predict the risk of stroke owing to the fact that clinical schemes to predict risk of stroke do not seem fully exhaustive [3]

On this basis an intriguing opportunity could be to evaluate the possible predictive value of some biomarkers towards ischemic stroke so as to integrate clinical schemes to improve their prognostic power.

Previous studies $[4,5,6]$ have shown that hypercoagulability was present in patients with non valvular atrial fibrillation (NVAF) by determining the levels of haemostatic markers. Moreover, evidence is growing that inflammation may be associated with AF [7] and it may underlie pathogenesis of the arrhythmia [8,9] and of cerebrovascular events. On this basis, we hypothesized that increased plasma levels of some immuno-inflammatory biomarkers would be associated with an increased risk of stroke in patients with NVAF. To test our hypothesis, we undertook a prospective study to determine rates of stroke in patients with NVAF, evaluating the relationship between plasma levels of some immuno-inflammatory variables at admission and the occurrence of stroke during a three year follow-up.

\section{Methods}

Patients with chronic non valvular AF consecutively admitted to the Division of Internal Medicine and Cardioangiology of the Policlinico "P.Giaccone" of Palermo from 1998 to 2003 were enrolled. 


\section{Patient Selection}

Chronic atrial fibrillation was definied [10] according to its temporal pattern based on the history of recurrent episodes and the duration of the current episode of AF with regard to two recognised patterns of chronic disease: "persistent atrial fibrillation" describes an episode of sustained atrial fibrillation (usually $>7$ days) that does not convert to sinus rhythm without medical intervention, with the achievement of sinus rhythm either by pharmacological or electrical cardioversion; "permanent atrial fibrillation" where episodes of persistent (usually $>1$ year) atrial fibrillation, in which cardio-version is not attempted or is unsuccessful, with atrial fibrillation accepted as the long term rhythm for that person.

Patients were excluded if they had: rheumatic AF or mechanical heart valves, acquired or congenital valvular disease (except mitral annulus calcification or mitral valve prolapse without mitral regurgitation), atrial fibrillation $<7$ days, echocardiographic evidence of intracardiac thrombosis or tumour, left ventricular aneurysm, severe congestive heart failure (New York Heart Association functional class $>I I I)$, a recent ( $<3$ months) myocardial infarction, unstable angina or stroke, carotid endarterectomy or coronary or peripheral revascularization procedures performed during the previous 6 months.

Other exclusion criteria were: neoplasms, connective tissue disorder, other chronic inflammatory diseases or a history of recent infection, patients who consumed regular nonsteroidal antiinflammatory drugs, corticosteroids, or hormone replacement therapy.

The study was approved by the Ethics Committee of the "Policlinico P.Giaccone" of Palermo. Written informed consent was obtained for all patients.

\section{Baseline}

At entry, each patient's medical history was taken and he/she underwent a physical examination. The following diagnostic procedures were also performed: routine blood laboratory tests, baseline 
12-lead ECG, M-mode, and 2-dimensional echocardiography with echocolor-doppler, echocolordoppler of the supra-aortic trunks, and chest roentgenography. Left ventricular hypertrophy (LVH) was defined as a value of LV mass indexed for height $\geq 51 \mathrm{gr}$ in both genders [11].

Patients were classified as known diabetic if they had been diagnosed as diabetics according diagnostic criteria of the Expert Committee on The Diagnosis and Classification of Diabetes Mellitus (i.e. a fasting glucose level of $\geq 7 \mathrm{mmol} / \mathrm{L}$ or a plasma glucose level of $\geq 11.1 \mathrm{mmol} / \mathrm{L}$ after glucose ingestion) [12] or if they are treated by diet, oral hypoglycemic drugs or insulin before hospital admission, whereas new-diagnosed diabetes were classified as 1997 ADA criteria [13]. Impaired fasting glucose tolerance (IFGT) was not considered .

Hypertension was defined according to 1993 World Health Organization criteria [systolic blood pressure $(S B P)>140$ and/or diastolic blood pressure $(D B P)>90 \mathrm{mmHg}$ in subject who are not taking antihypertensive medication or antihypertensive treatment on admission] [14]

Hypercholesterolemia was defined as total serum cholesterol $\geq 5.1 \mathrm{mmol} / \mathrm{L}$ and hypertrygliceridemia as total serum trigliceride $\geq 1.7 \mathrm{mmol} / \mathrm{L}$ on the basis of NCEP-ATP III reports $[15,16]$ that define this cut off for optimal total serum cholesterol and triglyceride levels.

We defined heart failure according to European Society of Cardiology criteria, namely as appropriate symptoms or signs of congestive heart failure (New York Heart Association functional class II or worse) plus objective evidence of cardiac dysfunction [17].

Atrial fibrillation duration was assessed by careful review of previous hospital records and, where necessary, liaison with general practitioners.

\section{Follow-Up}

Patients were periodically monitored (every 6 months) to assess compliance and clinical status and a record was made of the occurrence of outcome event (ischemic stroke). 
Stroke was defined as rapidly developing signs of focal or global disturbance of cerebral function, lasting $\geq 24$ hours, or leading to death, with no apparent cause other than that of vascular origin [18]. The occurrence of stroke was determined on the basis of clinical manifestations and confirmed by CT or MRI

\section{Outcome Events}

Patient events ( ischemic stroke at follow-up) were determined by careful review of hospital records and, where necessary, liaison with general practitioners to determine dates of stroke occurring during the intervening period (since initial blood sampling) during a three year follow-up.

\section{Blood Collection and Laboratory Analysis}

Blood samples from each subject enrolled were drawn in the morning within 72 hours of admission after an overnight fast from an antecubital vein by venipuncture into plastic tubes with $3.2 \%$ sodium citrate. They were centrifuged $(10,000 \mathrm{~g})$ and the resulting supernatant was immediately frozen at $80^{\circ} \mathrm{C}$ until analysis was completed. We evaluated plasma levels of IL- $1 \beta$, TNF- $\alpha$, IL-6, IL-10, Eselectin, P-selectin, ICAM-1, VCAM-1 and VWF.

IL-1 $\beta$, TNF- $\alpha$, IL-6 and IL-10 and VWF antigen were measured using a sandwich ELISA (Human IL-1 $\beta, T N F-\alpha, I L-6$ and IL-10 Quantikine, R\&D Systems) (VWF ELISA kit durian, Instrumentation Laboratory, Milano, Italy); VCAM-1, ICAM-1, E-selectin, P-selectin, were measured by commercial bioimmunoassay (Human sICAM-1, sVCAM-I, sE-selectin and sP-selectin Parameter, Quantikine, R\&D Systems ELISA Kit).

The minimum detectable concentrations for the diagnostic tests are: TNF alpha: $1.6 \mathrm{pg} / \mathrm{mL}$; IL-1 $\beta$ : $<1 \mathrm{pg} / \mathrm{mL}$; IL-6: <0.70 pg/mL; IL-10: <3.9 pg/mL; ICAM-1: <0.35 ng/mL; VCAM-1: $0.6 \mathrm{ng} / \mathrm{mL}$; E-Selectin: <0.1 ng/mL; P-Selectin: <0.5 ng/mL; vWF: $1.0 \%$.

Intraassay and interassay coefficients of variation were: TNF alpha:4.2\% and 4.6\%; IL-1 3 : $3.3 \%$ and 4.2\%; IL-6:1.6\% and 3.3\%; IL-10: $4.3 \%$ and 7.5\%; ICAM-1: 4.8\% and 6.1\%; VCAM-1: $3.5 \%$ and 7.7\%; E-Selectin: $4.8 \%$ and 5.7\%; P-Selectin: $4.9 \%$ and 8.8\%; vWF: $5 \%$ and $10 \%$. 


\section{Statistical Analysis}

For normally distributed variables, results are expressed as mean and standard deviations and for non-normally distributed data as median and interquartile range (IQR) values. Mann-Whitney U test and univariate analysis of variance test (ANOVA) were performed in order to compare nonnormally and normally distributed continuous variables, respectively. Chi-square and chi-square test for trend were used for categorical variables.

A Cox proportional-hazards regression model was used to evaluate adjusted and unadjusted predictive values of each clinical and laboratory variable at baseline to occurrence of the end point stroke during follow-up. The following variables, assessed at the baseline evaluation, were considered as potential predictors of ischemic events: age, male sex, hypertension, diabetes, dyslipidemia, CHF, previous stroke, plasma levels of TNF $\alpha$, IL6, IL-1 $\beta$, IL-10, E-Selectin, PSelectin, ICAM-1, V-CAM-1 and vWF.

Only variables that resulted significant on univariate analysis were included in the final multivariate model.

The best predictive model was composed using backward variable selection strategy, in which a probability value of $\mathrm{P}<0.05$ was applied for entering or removing a variable. In order to assess the predictive rate of different values of some studied continuous immuno-inflammatory variables for the determination of stroke outcome, a receiver operating characteristic (ROC) curve with their area under the curve (AUC) was constructed.

Survival curves free from stroke onset in relationship with quartiles of immuno-inflammatory variable plasma levels were generated by the Kaplan-Meier method.

All the analyses were evaluated in relation of anticoagulation or antiplatelet treatment and with regard of sex and previous stroke history.

Sample size calculation indicated a sample size of 350 to detect a minimal relative prognostic risk of 2.6 for patients with different levels of cytokines with a alfa error of 0.05 and a power of 0.80 and so we enrolled 373 patients. 
All statistical tests used were two-sided. Values of $\mathrm{P}<0.05$ were considered statistically significant. SPSS version 10.0 for Windows software (SPSS, Inc., Chicago, IL) was used for data analysis.

\section{Results}

We enrolled 451 patients with atrial fibrillation consecutively admitted to our Department of Internal and Specialist Medicine of the University of Palermo. We excluded, on the basis of exclusion criteria, 78 patients (18 for recent cardiovascular event, 30 for paroxysmal or atrial fibrillation with a duration $<7$ days atrial fibrillation, 10 for mechanical heart valves, 7 for inflammatory disease, 3 who used nonsteroidal anti-inflammatory drugs and 10 for cancer), so we limited biochemical evaluation of immunoinflammatory variables at baseline to 373 patients. The mean duration of atrial fibrillation at baseline was $3.2 \pm 1.8$ years.

$187(50,1 \%)$ were treated at the time of blood sampling with antivitamin-k antagonists and 88 patients $(23.5 \%)$ were treated with antiplatelet drugs (table 1$)$.

Median values of TNF $\alpha$, IL6, IL-1 $\beta$, IL-10, E-Selectin, P-Selectin, ICAM-1, V-CAM1 and vWF in patients with chronic atrial fibrillation are shown in table 2. No significant difference were observed between subjects with and without anticoagulant treatment. No significant difference was observed between enrolled subjects in relation to clinical risk factors (diabetes, hypertension, smoking, cholesterol, CAD, carotid plaque, left ventricular hypertrophy previous stroke) with regard to plasma levels of biomarkers.

Patients were followed up for 36 months ; the mean duration of follow-up at stroke onset was 22 \pm 9.7 months. During this follow-up period, there were $51(13.6 \%)$ ischemic strokes ( see table 1$)$. $38(74,05 \%)$ were detected by a CT scan, whereas $13(25,49 \%)$ by MRI .

\section{Univariate Analysis}

Among clinical and laboratory variables age, prior stroke, hypertension, diabetes congestive heart failure (CHF) and CRP were significantly associated with stroke onset at follow-up (see table 3) 
With regard to cytokine plasma levels, IL6, TNF- $\alpha$, vWF and IL1 $\beta$ were significantly associated with new onset stroke at follow-up (see table 3). Hazard ratios for quartiles with an analysis of $\mathrm{p}$ for trend are given in table 3.

\section{Multivariate analysis}

Multivariate data from Cox proportional hazards analysis for stroke are given in table 3

By incorporating as putative predictors all significant variables at univariate analysis, among clinical variables, only age and hypertension were associated with stroke at follow-up. Moreover high levels of IL6 (HR: 2.43; 95\% CI = 1.78-3.05; $\mathrm{p}=0.0001)$; TNF $\alpha$ (HR: $2.81 ; 95 \% \mathrm{CI}=1.80$ 3.70; $\mathrm{p}=0.0001$ ) and $\mathrm{vWF}$ (HR: 3.69; 95\% $\mathrm{CI}=1.96-4.53 ; \mathrm{p}=0.0001$ ) remained significantly associated with ischemic stroke at follow-up.

The relationships between chosen biomarkers and stroke risk at follow-up were the same for the groups with and without anticoagulant treatment,with and without antiplatelet treatment, for males and females and for the groups with and without previous stroke

\section{Kaplan Meyer Curves}

Kaplan-Meier curves were constructed to compare the survival curves of patients in the highest quartile of those immuno-inflammatory variables significantly associated with stroke at follow-up on multivariate analysis versus patients of the other quartiles. As shown in figures 1,2,3 higher plasma levels of IL-6, vWF and TNF- $\alpha$ are significantly associated with ischemic cerebrovascular events at follow-up.

\section{Receiver-Operating Characteristic (ROC) curves}

To provide a further demonstration of the predictive value of immuno-inflammatory markers that showed a significant association with new stroke incidence at follow-up we developed a multivariable logistic regression model. The plasma values of TNF- $\alpha$, IL6 and vWF showed a significant area under the ROC curve (respectively $0.77,0.74,0.81$ ). The best cut-off values for TNF- $\alpha(35 \mathrm{pg} / \mathrm{mL})$ had a $72.5 \%$ sensitivity and $75.7 \%$ specificity to predict new-onset stroke at 
follow-up. Cut-off values of $17 \mathrm{pg} / \mathrm{mL}$ and $6 \mathrm{pg} / \mathrm{mL}$ maximized sensitivity (66.6\% and 78.43\%) and specificity (77.6\% and 74.2\%) for IL-6 and vWF, respectively.

\section{Discussion}

In our study we report that baseline plasma levels of TNF- $\alpha$, IL-6 and vWF are associated with new onset ischemic stroke at follow-up in patients with chronic non-valvular atrial fibrillation (NVAF).

Previous studies suggested that markers of inflammation are elevated in patients with atrial fibrillation (AF) $[7,8,19]$. Nevertheless, no study, to our knowledge, evaluated the role of TNF- $\alpha$ in prediction of stroke in patients with NVAF, whereas some studies previously reported the association of IL-6 [9] and vWF baseline plasma values [20,21] with stroke at follow-up in these subjects.

However, in addition to these findings [9,20,21], our study, underlined the predictive role of three inflammatory variables such as TNF- $\alpha$, IL-6 and VWF as markers of inflammation and endothelial dysfunction involved in thrombogenesis. So our results encompass three main events of vascular damage: inflammation, endothelial dysfunction and thrombosis as predictive markers of future cardioembolic ischemic events and this could represent a novel finding. In particular, in our study, ROC curve analysis emphasizes the role of vWF plasma.

Cytokines such as IL-6 can induce a prothrombotic state by increasing expression of fibrinogen, tissue factor, factor VIII and von Willebrand factor, as well as by activating endothelial cells and increasing platelet production [22]. These findings may provide a link between inflammation and thrombosis and may explain the association of IL-6, TNF- $\alpha$ and VWF with ischemic stroke at follow-up in our patients with atrial fibrillation.

Nevertheless, it is possible to hypothesize that inflammatory markers could express not only a cardiac inflammatory background, but also inflammation and endothelial dysfunction of the recipient cerebral vessels and microvessel, in a context of atherosclerotic systemic vascular inflammation, so as to predispose brain arterial occlusion due to an embolus arising in the heart. 
What is the possible clinical and therapeutic involvement of this reported predictive power of some immuno-inflammatory markers in NVAF setting?

The rate of stroke in nonvalvular atrial fibrillation (AF) ranges widely and depends on the presence of prior cerebral ischemia, comorbid conditions, and use of antithrombotic therapy. Without antithrombotic therapy, the rate varies from fewer than 2 to more than 10 strokes per 100 patientyears. Thus, quantifying the risk of stroke is crucial for determining which AF patients would benefit most from warfarin therapy.

Several schemes exist to risk stratify subjects with NVAF to help select appropriate candidates for anticoagulant therapy, but their predictive abilities in patients receiving anticoagulant or antiplatelet treatment are unknown. Predicting which patients with atrial fibrillation will have a stroke or systemic embolic event is not an easy task. Baruch et al [23] compared 7 clinical risk stratification schemes in a large clinical trial-based program of patients with atrial fibrillation showing that all prediction schemes performed rather modestly.

So, in the future, a more accurate prediction rule for stroke may be possible by incorporating additional factors such as immunoinflammatory variables at baseline.

These immuno-inflammatory biomarkers could be one possible way to address the anticoagulant treatment or for a dose adjustment towards more "aggressive" doses or therapeutic targets in patients with higher levels of these variables potentially predictive of cerebrovascular events occurrence at follow-up

Our findings could suggest that, in patients with chronic NVAF, a combination of biomarkers such as TNF- $\alpha$, IL-6 and $\mathrm{VWF}$ at admission, could carry prognostic information towards new cerebrovascular events at three year follow-up. Furthermore, these results could reinforce the need to assess whether, in clinical practice, inflammatory biomarkers can be used to tailor optimal medical management of this subset of patients by addressing more intensive anticoagulation treatment in patients with higher plasma levels of immuno-inflammatory variables. 
A possible limitation of this study is that we cannot completely exclude the possibility that incidence of new onset stroke at follow-up may have been influenced by the use of antithrombotic therapy (most of the enrolled patients were receiving some form of antithrombotic therapy during the study). Nevertheless on multivariate analysis, adjusting for antithrombotic therapy, we showed no significant effect of antithrombotic treatment on the observed HR for each cytokine. Only point measurement could be another limitation of the study since repeated measures may be necessary to define the variance as well as predictive nature of a biomarker [24], but in support of our study, several studies previously reported the predictive value of only point measurement of inflammatory biomarkers in atrial fibrillation $[5,6,7,9]$

Moreover with our sample size it is possible to detect a minimal relative prognostic risk of 2.6 for patients with different levels of cytokines with an alfa error of 0.05 and a power of 0.80 . Nevertheless this is a prospective longitudinal study with a pathophysiologic background and on this basis our sample size would be plausible even without a prior evaluation of study size.

Finally, a possible question is how many of the observed strokes at follow-up are of cardioembolic origin. The predictive value of these cytokines was calculated for the simple endpoint ischemic stroke. Thus, it is unclear from our study whether TNF- $\alpha$, IL-6 and vWF are sensitive to ischemic cerebrovascular events of thromboembolic or also atherotrombotic origin. Larger sample size is, therefore, necessary to analyze the relationship between these immuno-inflammatory variables and each diagnostic subtype of ischemic stroke. Assuming that the patients were adequately anticoagulated the majority of "ischemic stroke" events could be related to atherosclerotic disease and not to embolism due to atrial fibrillation. Thus, the association of high cytokine levels with ischemic stroke could probably reflect more extensive cerebrovascular atherosclerotic disease in these patients in addition to indicating a possible link between inflammation and cardiac embolism. However, even in adequately anticoagulated patients embolic events are commonly registered. Evans A. et al. [25] in 392 patients with NVAF considered for adjusted-dose warfarin and followed up for 2 years reported a rate of stroke incidence respectively of $9.5 \%$ and $4.9 \%$ showing that stroke 
rate was due predominantly to cardioembolic recurrence in patients presenting initially with cardioembolic stroke. So it's plausible that most of the observed events in our enrolled subjects could be of cardioembolic origin.

In conclusion, our study showed that baseline plasma levels of TNF- $\alpha$, IL- 6 and vWF are associated with new onset ischemic stroke at follow-up in patients with chronic non valvular atrial fibrillation so encompassing three markers of inflammation, endothelial dysfunction and thrombosis as predictive markers of future cerebral ischemic events.

\section{References}

1. Kannel B, Wolf PA, Benjamin EJ, Levy D. Prevalence, incidence, prognosis, and predisposing conditions for atrial fibrillation: population-based estimates. Am J Cardiol. $1998 ; 82(8 \mathrm{~A}): 2 \mathrm{~N}-9 \mathrm{~N}$.

2. Atrial Fibrillation Investigators. Echocardiographic predictors of stroke in patients with atrial fibrillation: a prospective study of 1,066 patients from 3 clinical trials. Arch Intern Med 1998; 158:1316-1320.

3. Baruch L, Gage BF, Horrow J, Juul-Moller S, Labovitz A, Persson M, Zabalgoitia M. Can patients at elevated risk of stroke treated with anticoagulants be further risk stratified? A comparison of seven stroke prediction schemes. Stroke 2007;38:2459-2463.

4. Inoue H, Nozawa T, Okumura K, Jong-Dae L, Shimizu A, Yano K. Prothrombotic Activity Is Increased in Patients With Nonvalvular Atrial Fibrillation and Risk Factors for Embolism. CHEST 2004; 126:687-692.

5. Lip GY, Lip PL, Zarifis J, Watson RD, Bareford D, Lowe GD, Beevers DG. Fibrin d-dimer and beta-thromboglobulin as markers of thrombogenesis and platelet activation in atrial fibrillation: effects of introducing ultra-low-dose warfarin and aspirin. Circulation 1996; 94 : $425-431$. 
6. Lip GY, Lowe GD, Rumley A, Dunn FG. Fibrinogen and fibrin d-dimer levels in paroxysmal atrial fibrillation: evidence for intermediate elevated levels of intravascular thrombogenesis. Am Heart J 1996; 131:724-730;

7. Chung MK, Martin DO, Sprecher D, Wazni O, Kanderian A, Carnes CA, Bauer JA, Tchou PJ, Niebauer MJ, Natale A, Van Wagoner DR. C-reactive protein elevation in patients with atrial arrhythmias: inflammatory mechanisms and persistence of atrial fibrillation. Circulation 2001;104: 2886-91;

8. Frustaci A, Chimenti C, Bellocci F, Morgante E, Russo MA, Maseri A.. Histological substrate of atrial biopsies in patients with lone atrial fibrillation. Circulation 1997;96:11804.

9. Conway DS, Buggins P, Hughes E, Lip GY.Prognostic significance of raised plasma levels of interleukin-6 and C-reactive protein in atrial fibrillation. Am Heart J. 2004 Sep;148(3):462-6.

10. Lévy S, Camm AJ, Saksena S, Aliot E, Breithardt G, Crijns H, Davies W, Kay N, Prystowsky E, Sutton R, Waldo A, Wyse DG; Working Group on Arrhythmias, Working Group on Cardiac Pacing of the European Society of Cardiology, North American Society of Pacing and Electrophysiology. International consensus on nomenclature and classification of atrial fibrillation; a collaborative project of the Working Group on Arrhythmias and the Working Group on Cardiac Pacing of the European Society of Cardiology and the North American Society of Pacing and Electrophysiology. Europace 2003;5:119-122.

11. Devereux RB, Roman MJ (1995) Evaluation of cardiac and vascular structure and function by echocardiography and other non-invasive techniques. In: Laragh JH, Brenner BM, (eds) Hypertension: Pathophysiology, Diagnosis and Management, 2nd Edition. New York, Raven Press, pp 281-289. 
12. Expert commettee on the diagnosis and classification of diabetes mellitus. Report of the Expert Commettee on the diagnosis and classification of diabetes mellitus. Diabetes Care 1998;21:S5-S19

13. The Expert Comittee on the Diagnosis and Classification of Diabetes Mellitus: Report of the Expert Comittee on the diagnosis and classification of diabetes mellitus. Diabetes Care: 1997; 20, 1 183-97.

14. Zanchetti A, Chalmers JP, Arakawa K, Gyarfas I, Hamet P, Hansson L, Julius S, MacMahon S, Mancia G, Menard J, The 1993 guidelines for the management of mild hypertension: memorandum from a WHO/ISH meeting. Blood Press. 1993 Jun; 2(2):86-100 .

15. Drown DJ, Engler MM. New guidelines for blood cholesterol by the National Cholesterol Education Program (NCEP). National Cholesterol Education Program (NCEP). Prog Cardiovasc Nurs. 1994 Winter;9(1):43-4.

16. National Cholesterol Education Program Panel, Second Report of the Expert Panel on Detection, Evaluation, and Treatment of High Blood Cholesterol in Adults (Adult Treatment Panel)II. Circulation 1994 Mar; 89(3):1333-445.

17. Task Force on Heart Failure of the European Society of Cardiology. Guidelines for the diagnosis of heart failure. Eur Heart J 1995;16:74151.

18. Aho K, Armussen P, Hatano S, Marquardsen J, Smirnov VE, Strasser T. Cerebrovascular disease in the community: results of a WHO collaborative study. Bull World Health Organ. $1980 ; 58: 113-130$.

19. Marcus GM, Whooley MA, Glidden DV, Pawlikowska L, Zaroff JG, Olgin JE Interleukin-6 and atrial fibrillation in patients with coronary artery disease: data from the Heart and Soul Study.Am Heart J. 2008 Feb;155(2):303-9.

20. Lip GY Lane D, Van Walraven C, Hart RG .Additive role of plasma von Willebrand factor levels to clinical factors for risk stratification of patients with atrial fibrillation.Stroke. 2006 Sep;37(9):2294-300. Epub 2006 Aug 3. Erratum in: Stroke. 2006 Sep;37(9):2444. 
21. Roldán V, Marín F, García-Herola A, Lip GY. Correlation of plasma von Willebrand factor levels, an index of endothelial damage/dysfunction, with two point-based stroke risk stratification scores in atrial fibrillation. Thromb Res. 2005;116(4):321-5.

22. Kerr R, Stirling D, Ludlam CA. Interleukin 6 and haemostasis. Br J Hematol 2001;115:312. 11 .

23. Baruch L, Gage BF, Horrow J, Juul-Moller S, Labovitz A, Persson M, Zabalgoitia M. Can patients at elevated risk of stroke treated with anticoagulants be further risk stratified? A comparison of seven stroke prediction schemes. Stroke 2007;38:2459-2463.

24. MacFadyen RJ Intraindividual temporal variance of biomarkers and the definition of individualized prognosis in cardiovascular patients. J Hum Hypertens.2006 Jun;20(6):383-6.

25. Evans A, Perez I, Yu G, Kalra L Should Stroke subtype influence anticoagulation decisions to prevent recurrence in stroke patients with atrial fibrillation Stroke 2001; 32:2828-32. 
Table 1: Demographic and clinical variables in NVAF patients

\begin{tabular}{|c|c|}
\hline $\operatorname{Sex}(M / W)$ & $237 / 136(63.5 / 34.6)$ \\
\hline Age (years) & $66.08 \pm 7.35$ \\
\hline Hypertension (n/\%) & $270(72)$ \\
\hline Diabetes (n/\%) & $164(43.9)$ \\
\hline CAD $(n / \%)$ & $208(55.7)$ \\
\hline LVH (n/\%) & $119(31.9)$ \\
\hline CHF (n/\%) & $88(23.5)$ \\
\hline Smoking habit $(\mathrm{n} / \%)$ & $124(33.15)$ \\
\hline Carotid plaque (n/ \%) & $90(24.1)$ \\
\hline Previous stroke (n/ \%) & $34(9.1)$ \\
\hline $\begin{array}{r}\text { Medications at at the time of blood sampling } \\
\text { Antiplatelet treatment } \\
\text { Vitamin-K-antagonists } \\
\text { Heparine } \\
\text { Statins } \\
\text { ACE inhibitors } \\
\text { Angiotensin type-1 receptor blockers } \\
\text { Calcium antagonists } \\
\text { Beta blockers } \\
\text { Diuretics } \\
\text { Digitalis }\end{array}$ & $\begin{array}{c}88(23.5) \\
187(50,1) \\
10(2.6) \\
80(21.45) \\
171(45.84) \\
57(15.28) \\
187(50.73) \\
101(27.07) \\
181(48.52) \\
202(54.11)\end{array}$ \\
\hline $\begin{array}{r}\text { Medications at discharge } \\
\text { Antiplatelet treatment } \\
\text { Vitamin-K-antagonists } \\
\text { Heparine } \\
\text { Statins } \\
\text { ACE inhibitors } \\
\text { Angiotensin type-1 receptor blockers } \\
\text { Calcium antagonists } \\
\text { Beta blockers } \\
\text { Diuretics } \\
\text { Digitalis }\end{array}$ & $\begin{array}{c}122(33.8) \\
251(67.2) \\
0(0) \\
95(25.46) \\
154(41.28) \\
89(23.86) \\
201(53.8) \\
122(32.7) \\
193(51.74) \\
134(35.92)\end{array}$ \\
\hline $\begin{array}{l}\text { SBP }(\mathrm{mm} / \mathrm{Hg})(\text { mean } \pm d s)(\mathrm{n}: 373) \\
\text { DBP }(\mathrm{mm} / \mathrm{Hg})(\text { mean } \pm d s)(\mathrm{n}: 373)\end{array}$ & $\begin{array}{c}136 \pm 6.8 \\
87 \pm 4.5\end{array}$ \\
\hline EF $(\%)($ mean \pm ds) $($ n: 373$)$ & $48 \pm 3$ \\
\hline $\begin{array}{r}\text { New onset ischemic stroke at follow-up ( fatal and not fatal) }(\mathbf{n} / \%) \\
\text { Fatal stroke }(\mathbf{n} / \%)\end{array}$ & $\begin{array}{c}51(13.6) \\
5(9.8)\end{array}$ \\
\hline
\end{tabular}

Dichotomic variables are expressed as frequence $(n / \%)$; Continous variables are expressed as mean \pm ds. CAD: Coronary Artery Disease; LVH: left ventricular Hypertrophy; CHF: congestive heart failure SBP: Systolic blood pressure; DBP: diastolic blood pressure; EF: Ejection Fraction

Licenced copy. Copying is not permitted, except with prior permission and as allowed by law. 
Table 2: laboratory and immuno-inflammatory variables at baseline in NVAF patients

\begin{tabular}{|l|l|}
\hline Total Cholesterol (mmol/L) (n: 373) & $4.706 \pm 0.97$ \\
LDL-cholesterol ( mmol/L ) (n: 373) & $2.80 \pm 1.08$ \\
HDL-cholesterol (mmol(L) (n: 373) & $1.1 \pm 0.3$ \\
\hline Triglyceride (mmol/L ) (n: 373) & $1.22 \pm 0.54$ \\
\hline CRP (mg/dl) & $2.48(1.5-3.4)$ \\
\hline TNF- $\boldsymbol{\alpha}$ (pg/ml) (n: 373) & $26(8-45)$ \\
\hline IL-1 $\boldsymbol{\beta}$ (pg/ml) (n: 373) & $3(1-12)$ \\
\hline IL-6 (pg/ml) (n: 373) & $11 \pm(1-36)$ \\
\hline IL-10 (pg/ml) (n: 373) & $4 \pm(0.8-18)$ \\
\hline E-Selectin (pg/ml) (n: 373) & $2(0.4-8)$ \\
\hline P-Select (pg/ml) (n: 373) & $3 .(0.5-10)$ \\
\hline ICAM-1 (pg/ml) (n: 373) & $15.60(0.8-31)$ \\
\hline V-CAM-1(pg/ml) (n: 373) & $14(3-22)$ \\
\hline vWF (pg/ml) (n: 373) & $4(0.4-12)$ \\
\hline
\end{tabular}

Continous variables are expressed as mean $\pm d s$; normally distributed variables were expressed as median and percentiles (first and third quartiles). CRP: C-reactive protein; Tumor Necrosis Factor $\alpha$; IL-1 $\beta$ : Interleukin-1 $\beta$; IL-6: Interleukin-6; IL-10: Interleukin 10; ICAM-1: intercellular adhesion molecule-1; V-CAM-1: vascular cell adhesion molecule-1; vWF: von Willebrand Factor.

Licenced copy. Copying is not permitted, except with prior permission and as allowed by law. 
Table 3 - Univariate and multivariate Cox analysis adjusted for age (with 95\% CI) about the relative contribution of each clinical and laboratory variable at baseline to occurrence of the end point stroke during followup and hazard ratios for quartiles with the analyse of $p$ for trend.

\begin{tabular}{|c|c|c|c|c|c|}
\hline \multicolumn{3}{|c|}{ Univariate analysis } & & & \\
\hline & HR $(95 \% \mathrm{CI}$ & $\mathbf{p}$ & & & \\
\hline Age & $1.87(1.10-2.98)$ & 0.0001 & & & \\
\hline Hypertension & $1.33(1.12-1.85)$ & 0.03 & & & \\
\hline Diabetes & $1.37(1.52-3.11)$ & 0.04 & & & \\
\hline CHF & $1.38(1.13-1.94$ & 0.032 & & & \\
\hline Previous stroke & $2.60(1.49-3.49)$ & 0.0001 & & & \\
\hline Smoking habit & $0.85(0.50-1.02)$ & 0.55 & & & \\
\hline CAD & $0.75(0.50-1.22)$ & 0.25 & & & \\
\hline LVH & $0.35(0.26-1.02)$ & 0.65 & & & \\
\hline CRP & $1.55(1,21-2.35)$ & 0.039 & & & \\
\hline Il-10 & $0.79(0.20-1.02)$ & 0.35 & & & \\
\hline ICAM-1 & $0.45(0.36-1.03)$ & 0.21 & & & \\
\hline VCAM-1 & $0.95(0.40-1.12)$ & 0.66 & & & \\
\hline P-selectin & $0.59(0.25-1.11)$ & 0.38 & & & \\
\hline E-selectin & $0.55(0.26-1.02)$ & 0.65 & & & \\
\hline & & & & $\begin{array}{c}\text { HR for } \\
\text { quartiles }\end{array}$ & $\begin{array}{l}\text { p for } \\
\text { trend * }\end{array}$ \\
\hline IL1- $\beta$ & $1.21(1.00-1.54)$ & 0.036 & $\begin{array}{l}\text { Quartile 1 } \\
\text { Quartile 2 } \\
\text { Quartile 3 } \\
\text { Quartile 4 }\end{array}$ & $\begin{array}{l}1.0 \\
2.16 \\
0.63 \\
4.43\end{array}$ & 0.056 \\
\hline IL6 & $1.93(1.02-2.05)$ & 0.0001 & $\begin{array}{l}\text { Quartile 1 } \\
\text { Quartile } 2 \\
\text { Quartile } 3 \\
\text { Quartile } 4 \\
\end{array}$ & $\begin{array}{l}1.0 \\
0.26 \\
2.11 \\
9.37 \\
\end{array}$ & $<0.0005$ \\
\hline TNF- $\alpha$ & $2.07(1.72-2.98)$ & 0.0001 & $\begin{array}{l}\text { Quartile } 1 \\
\text { Quartile } 2 \\
\text { Quartile } 3 \\
\text { Quartile } 4\end{array}$ & $\begin{array}{l}1.0 \\
2.67 \\
18.18 \\
14.29\end{array}$ & $<0.0005$ \\
\hline VWF & $2.86(1.73-3.04)$ & 0.0001 & $\begin{array}{l}\text { Quartile } 1 \\
\text { Quartile } 2 \\
\text { Quartile } 3 \\
\text { Quartile } 4 \\
\end{array}$ & \begin{tabular}{|l|}
1.0 \\
1.42 \\
7.14 \\
308.00 \\
\end{tabular} & $<0.0005$ \\
\hline
\end{tabular}

\begin{tabular}{|l|c|c|}
\hline \multicolumn{3}{|c|}{ Multivariate analysis } \\
\hline & HR (95\% CI) & p \\
\hline Age & $1.94(0.76-2.69)$ & 0.005 \\
\hline Hypertension & $1.83(1.01-2.55)$ & 0.005 \\
\hline Diabetes & $0.81(0.20-1.32)$ & 0.06 \\
\hline CHF & $0.69(0.26-1.53)$ & 0.43 \\
\hline Previous stroke & $0.55(0.38-1.25)$ & 0.26 \\
\hline CRP & $0.89(0.56-1.21)$ & 0.059 \\
\hline IL-1 $\beta$ & $0.85(0.63-1.33)$ & 0.06 \\
\hline IL6 & $2.43(1.78-3.05)$ & 0.0001 \\
\hline TNF- $\alpha$ & $2.81(1.80-3.70)$ & 0.0001 \\
\hline vWF & $3.69(1.96-4.5)$ & 0.0001
\end{tabular}

CHF: congestive heart failure; CAD: Coronary Artery Disease; LVH: left ventricular Hypertrophy; CRP: C-reactive protein; TNF- $\alpha$ : Tumor Necrosis Factor $\alpha$; IL-1 $\beta$ : Interleukin-1- $\beta$; IL-6: Interleukin-6; IL-10: Interleukin 10; ICAM-1: intercellular adhesion molecule-1; V-CAM-1: vascular cell adhesion molecule-1; vWF: von Willebrand Factor.

*p for trend for quartiles are given for immunoinflammatory variables significantly associated with stroke at univariate analysis.

Licenced copy. Copying is not permitted, except with prior permission and as allowed by law. 


\section{Figure 1 :Kaplan-Meier analysis. Ischemic stroke-free survival by IL-6 quartiles}

\section{IL-6 quartiles}

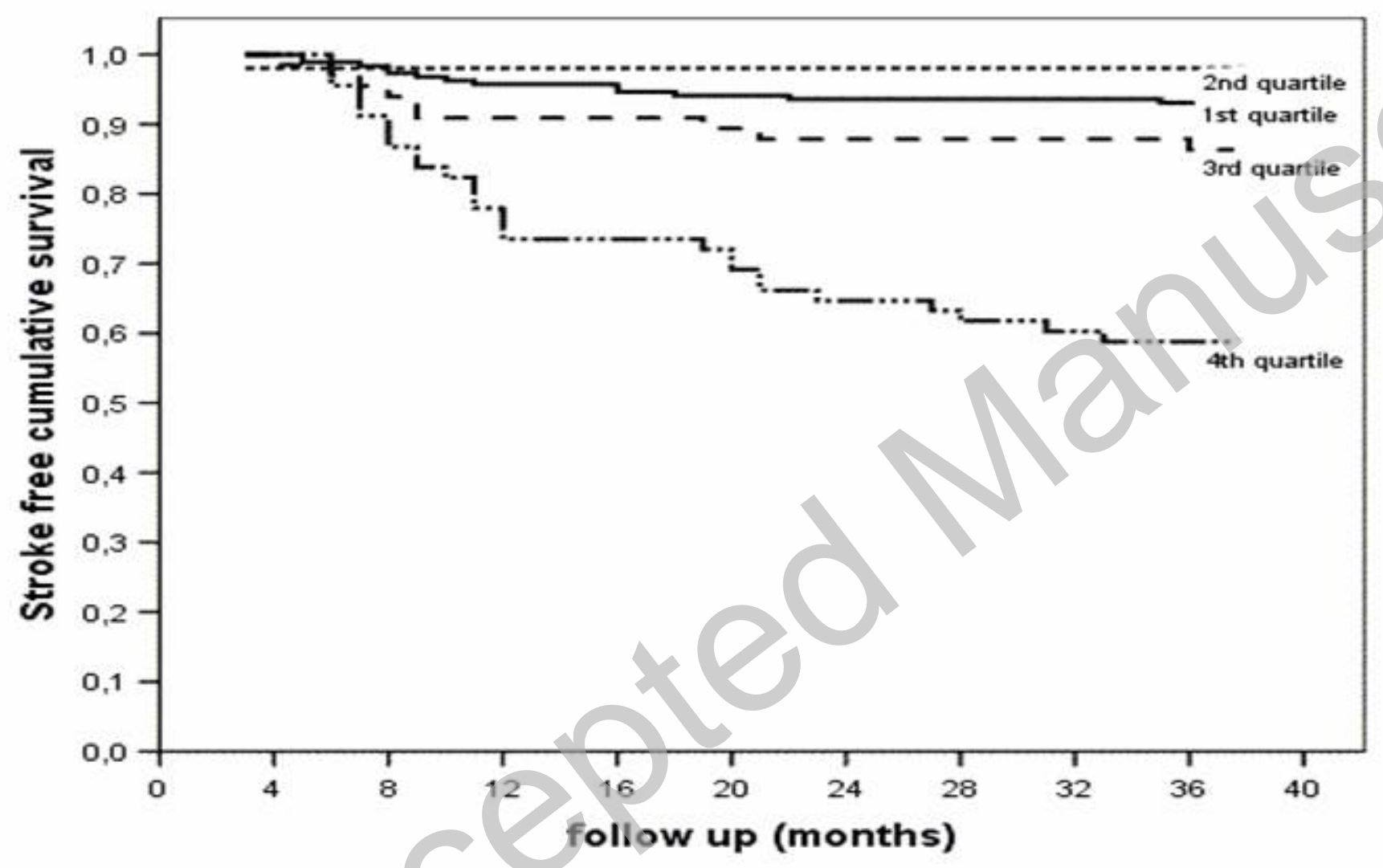

\begin{tabular}{|c|c|c|c|c|c|}
\hline \multicolumn{6}{|c|}{ Number at risk / events at each time of follow-u } \\
\hline IL -6 & month 6 & month 12 & month 18 & month 24 & month 36 \\
\hline $\begin{array}{l}\text { Quartile } 1 \text { (n: 187) } \\
\text { Quartile } 2 \text { (n:52) } \\
\text { Quartile } 3 \text { (n: 66) } \\
\text { Quartile } 4 \text { (n:68) }\end{array}$ & $\begin{array}{l}185 / 2 \\
51 / 1 \\
64 / 2 \\
65 / 3\end{array}$ & $\begin{array}{l}179 / 6 \\
51 / 0 \\
60 / 4 \\
50 / 15\end{array}$ & $\begin{array}{c}176 / 3 \\
51 / 0 \\
60 / 0 \\
50 / 0\end{array}$ & $\begin{array}{l}175 / 1 \\
51 / 0 \\
58 / 2 \\
44 / 6\end{array}$ & $\begin{array}{c}174 / 1 \\
51 / 0 \\
57 / 1 \\
40 / 4\end{array}$ \\
\hline
\end{tabular}

Licenced copy. Copying is not permitted, except with prior permission and as allowed by law. 


\section{Fiqure 2 :Kaplan-Meier analvsis. Ischemic stroke-free survival bv TNF- $\alpha$ quartiles}

\section{TNF-alfa quartiles}

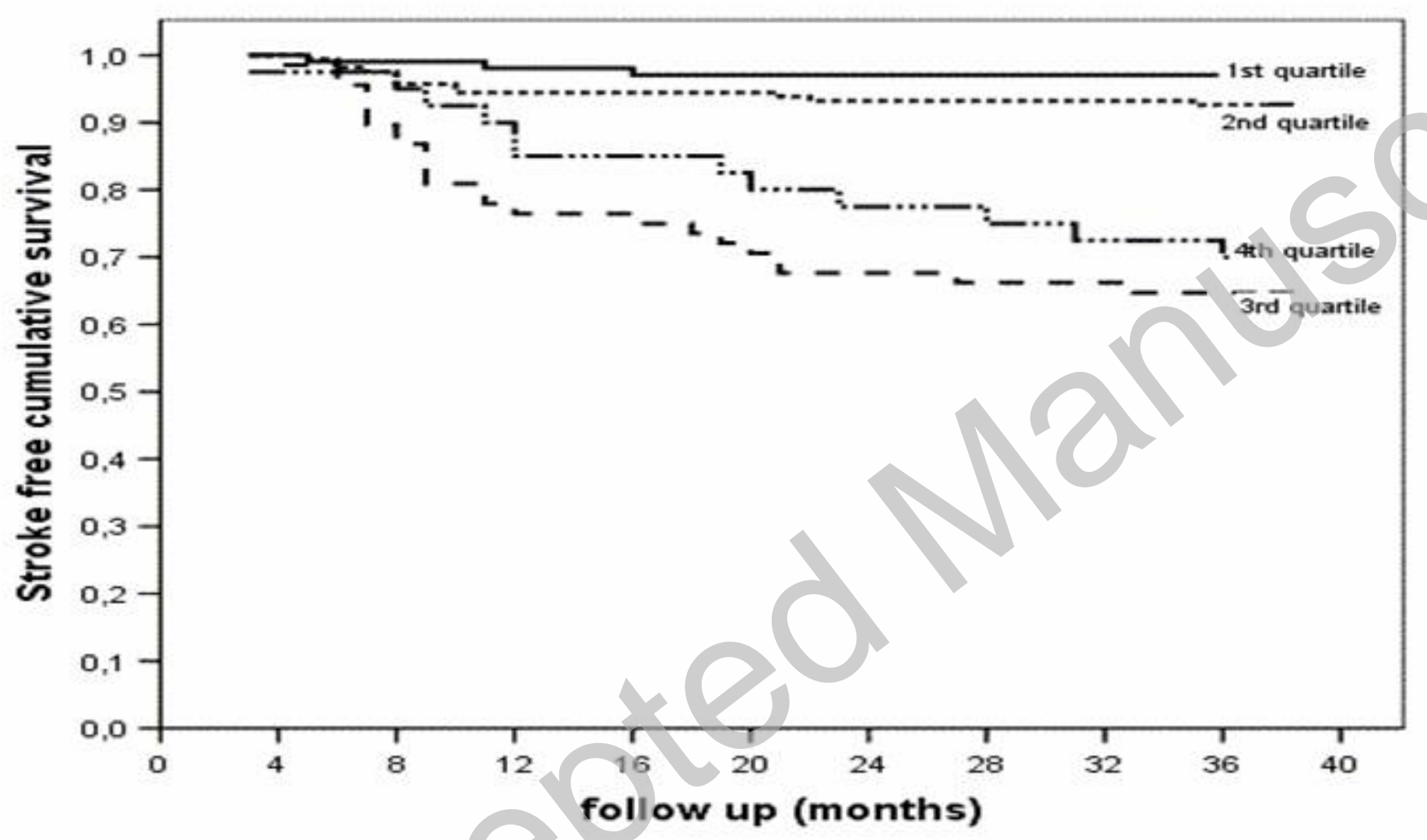

Frequencies for quartiles

\begin{tabular}{|l|l|}
\hline Quartile1 & 103 \\
\hline Quartile2 & 162 \\
\hline Quartile 3 & 68 \\
\hline Quartile 4 & 40 \\
\hline total & 373 \\
\hline
\end{tabular}

\begin{tabular}{|c|c|c|c|c|c|}
\hline \multicolumn{6}{|c|}{ Number at risk and events at each time } \\
\hline TIIF-ax & $\begin{array}{c}\text { month6 } \\
\mathrm{N}^{\circ} \text { at riskiserent }\end{array}$ & $\begin{array}{c}\text { month } 12 \\
N^{\circ} \text { at riskserent }\end{array}$ & $\begin{array}{c}\text { month } 18 \\
\mathrm{~N}^{\circ} \text { at riskierent }\end{array}$ & $\begin{array}{c}\text { month } 24 \\
\mathrm{~N}^{\circ} \text { at riskiserent }\end{array}$ & $\begin{array}{c}\text { month } 36 \\
N^{\circ} \text { at riskievent }\end{array}$ \\
\hline $\begin{array}{l}\text { Quartile } 1 \\
\text { Quartile 2 } \\
\text { Quartile 3 } \\
\text { Quartile 4 }\end{array}$ & $\begin{array}{l}102 / 1 \\
159 / 3 \\
65 / 3 \\
39 / 1\end{array}$ & $\begin{array}{l}101 / 1 \\
153 / 6 \\
52 / 13 \\
34 / 5\end{array}$ & $\begin{array}{l}100 / 1 \\
153 / 0 \\
50 / 2 \\
34 / 0\end{array}$ & $\begin{array}{l}100 / 0 \\
151 / 2 \\
46 / 4 \\
31 / 3\end{array}$ & $\begin{array}{l}100 / 0 \\
150 / 1 \\
44 / 2 \\
28 / 3\end{array}$ \\
\hline
\end{tabular}

Licenced copy. Copying is not permitted, except with prior permission and as allowed by law.

(C) 2008 The Authors Journal compilation (C) 2008 Biochemical Society 
Figure 3 :Kaplan-Meier analysis. Ischemic stroke-free survival by vWF quartiles

WWF quartiles

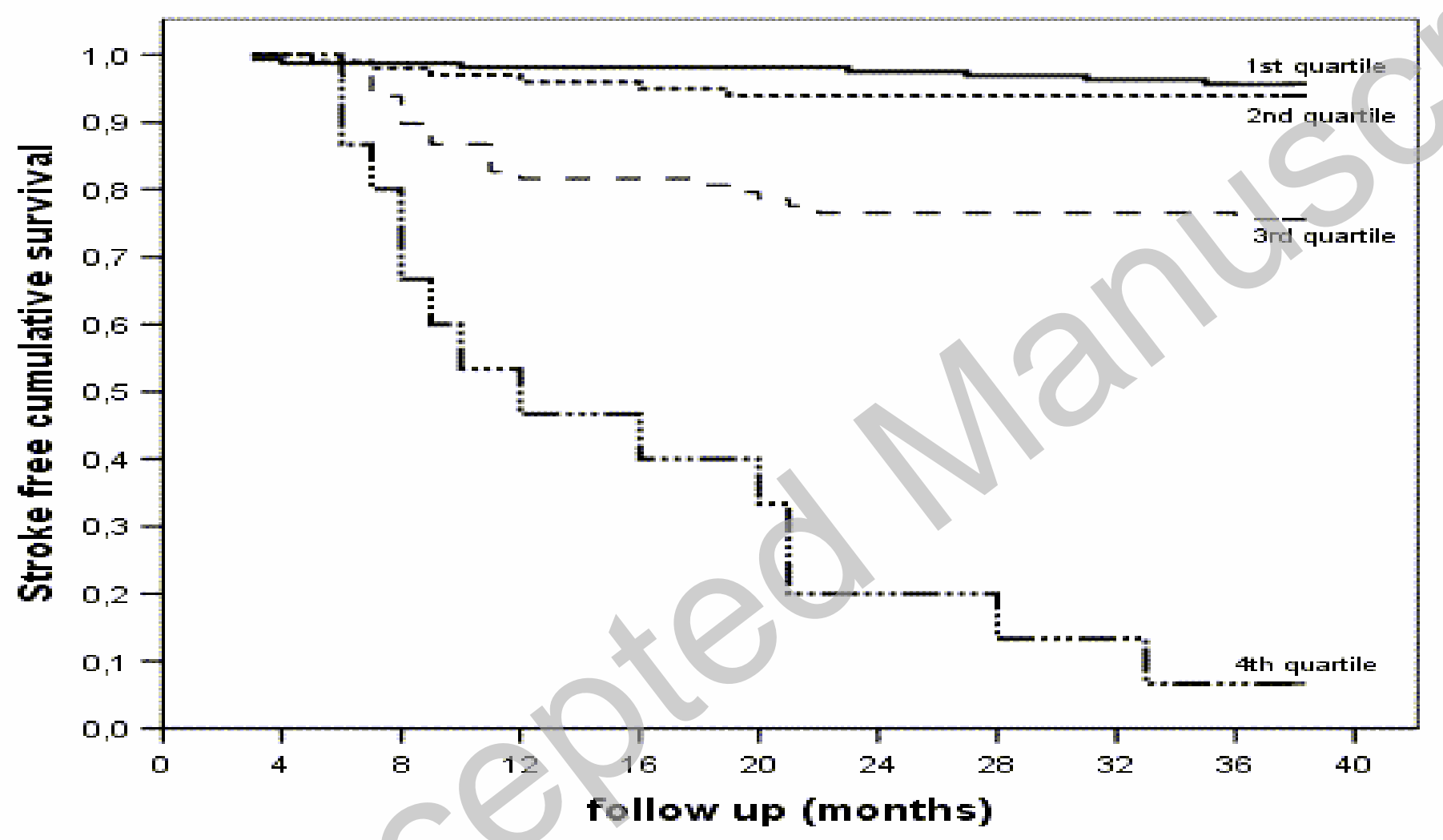

\begin{tabular}{|c|c|c|c|c|c|}
\hline \multicolumn{6}{|c|}{ Number at risk / events at each time of follow-up } \\
\hline vWF & month 6 & month 12 & month 18 & month 24 & month 36 \\
\hline $\begin{array}{ll}\text { Quartile } 1 & (n: 161 \\
\text { Quartile } 2 & (n: 99) \\
\text { Quartile } 3 & \text { (n: 98) } \\
\text { Quartile } 4 & (n: 15)\end{array}$ & $\begin{array}{c}159 / 2 \\
98 / 1 \\
95 / 3 \\
13 / 2\end{array}$ & $\begin{array}{c}158 / 1 \\
95 / 3 \\
80 / 15 \\
7 / 6\end{array}$ & $\begin{array}{c}158 / 0 \\
94 / 1 \\
79 / 1 \\
6 / 1\end{array}$ & $\begin{array}{c}157 / 1 \\
93 / 1 \\
75 / 4 \\
3 / 3\end{array}$ & $\begin{array}{c}154 / 3 \\
93 / 0 \\
74 / 1 \\
1 / 2\end{array}$ \\
\hline
\end{tabular}

Licenced copy. Copying is not permitted, except with prior permission and as allowed by law.

(C) 2008 The Authors Journal compilation (c) 2008 Biochemical Society 